\title{
Identidade nacional na Boêmia do século XV e a formação de uma paideia tcheca'
}

Thiago Borges de Aguiar"

Davi Costa da Silvall"

I- Esta pesquisa contou com financiamento da Fundação de Amparo à Pesquisa do Estado de São Paulo (FAPESP), na modalidade bolsa de pós-doutorado, da Fundação de Apoio à Faculdade de Educação (FAFE-FEUSP), na modalidade bolsa de iniciação científica, e do Conselho Nacional de Desenvolvimento Científico e Tecnológico (CNPq).

II- Universidade Metodista de Piracicaba, Piracicaba, SP, Brasil. Contato: tbaguiar@unimep.br

III- Universidade de São Paulo, São Paulo, SP, Brasil.

\section{Resumo}

No presente artigo, buscamos analisar a formação de um ideal de tchequidade tendo como foco o século XV. Para tanto, apoiados na historiografia a respeito do final da Idade Média, refletimos primeiramente acerca da possibilidade do uso dos termos nação e correlatos para referenciar-nos a esse período, mostrando como a associação entre os termos língua e nação é lembrada por pesquisadores. Na sequência, mostramos como essa associação ajuda a compreendermos o caso da nacionalização da Universidade de Praga, a partir do Decreto de Kutná Hora de 1409, acordado entre o rei Václav IV e a nação tcheca da universidade, visando a torná-la preponderante sobre as outras nações. Após a descrição do hussitismo e das guerras religiosas que se espalharam pelas terras históricas tchecas no início do século XV, refletimos a respeito da importância desse momento histórico para a formação de um ideal de nacionalidade tcheca, transmitido na forma de uma herança coletiva e de um conteúdo a ser ensinado às futuras gerações. Assim, tomamos de empréstimo o termo paideia para interpretar o ideal de tchequidade formado no período hussita e indicar seu alcance e futura apropriação por tchecos - desde a União dos Irmãos e Comenius a Tomáš Garrigue Masaryk, primeiro presidente da República Tchecoslováquia.

\section{Palavras-chave}

Educação tcheca - Tchequidade - Nação - Hussitismo. 


\title{
National identity in fifteenth century Bohemia and the formation of a Czech Paideia
}

Thiago Borges de Aguiar'

Davi Costa da Silva"

\begin{abstract}
In this article, we analyze the formation of an ideal of Czechness in the fifteenth century. Here, supported by the late Middle Ages historiography, we first reflect about the possibility of using the terms nation and others related to it to refer to that period, showing how the association between the terms language and nation is remembered by researchers. Next, we show how this association helps to understand the nationalization of the University of Prague, which occurred at the Decree of Kutna Hora, 1409, agreed upon by the King Wenceslas IV and the university's Czech nation aiming to make it dominant over the other nations. After a description of Hussitism and religious wars that spread through the Czech historical lands in the early fifteenth century, we reflect on the importance of this historic moment for the formation of an ideal of Czech nationality, transmitted in the form of a collective heritage and a content to be taught to future generations. Thus, we borrow the term Paideia to interpret the ideal of Czechness formed in the Hussite period and indicate its scope and future appropriation by the Czechs - since the Czech Brethren and Comenius to Tomás Garrigue Masaryk, the first president of Czechoslovakia Republic.
\end{abstract}

\section{Keywords}

Czech education - Czechness - Nation - Hussitism.

I- Universidade Metodista de Piracicaba 


\section{Introdução}

É possivel falarmos em nações e sentimento nacional na Europa do final da Idade Média? Essa é a pergunta com a qual iniciamos este artigo. Mas não nos propomos aqui a resolver essa questão, que já está em pauta há algumas décadas na produção historiográfica europeia. Partimos dela para pensarmos a possibilidade de associarmos um sentimento nacional à construção de um conjunto formativo de agentes, instituições, textos, ideias e ações em um determinado espaço e tempo. É seguindo as consequências dessa pergunta que construímos, neste artigo, um estudo acerca da ideia de nação tcheca no século XV e suas consequências educacionais.

0 caso da nação tcheca é relevante para ser estudado. Em primeiro lugar, as terras históricas tchecas ${ }^{1}$ não fazem parte da história hegemônica, muito centrada nas histórias francesa, inglesa, alemã e italiana. Em segundo lugar, os conflitos religiosos, intensificados a partir do Concílio de Constança (1414-1418), fizeram das terras históricas tchecas um lugar religiosamente isolado, ajudando a fortalecer a formação de uma identidade nacional. Por fım, a cidade de Praga, capital da Boêmia, foi o local onde se instituiu a primeira universidade nacional nos modelos da universidade medieval.

Essa identidade nacional é formativa. Ela constitui um sentimento coletivo que, ao mesmo tempo em que agrega pessoas, normatiza padrões de comportamento, fortalece a língua nacional e exige a constituição de agentes educadores. Não estamos falando aqui de instituições escolares, embora elas estejam presentes. Neste texto, enfatizamos a constituição de um conteúdo a ser ensinado, de um ideal de homem, sem deixar de lado alguns dos sujeitos educadores. É nesse sentido que estamos tomando por empréstimo o termo paideia - profundamente analisado por Jaeger

1- Consistem nas regiões da Boêmia, Morávia, Silésia e Lusácia, esta última se germanizando ainda no século XIV. A primeira, historicamente, destaca-se no período e é o centro de nossas reflexões neste artigo.
(2001) - para pensarmos de modo amplo a formação do povo tcheco.

Desse modo, depois de discutirmos a possibilidade do uso do conceito de nação no fınal da Idade Média, com ênfase na região das terras históricas tchecas, concentraremos nossa atenção no início do século XV, com a efetiva nacionalização da Universidade de Praga. Então, poderemos discutir uma reunião de elementos que nos ajudem a perceber o fortalecimento do sentimento nacional como constituição de uma paideia tcheca. Essa é nossa proposta para este texto.

\section{Nacionalismo e nação tcheca}

A historiografia tende a, tradicionalmente, colocar o surgimento dos estados nacionais no período da Modernidade e a recusar a ideia de sentimento nacional no período medieval. No entanto, observamos que um dos problemas centrais para se caracterizar as origens do nacionalismo e das nações (ou vice-versa, dependendo do autor que formula essa questão) envolve definir os limites físicos e culturais dentro dos quais as pessoas se consideram parte de um mesmo grupo. Uma nação normalmente requer a imaginação de uma comunidade territorialmente grande que englobe aquelas nas quais um indivíduo circula diariamente.

De acordo com Seltzer (2005, p. 217 e seguintes) e Scales (1999, p. 328 e seguintes), apesar de sua longa tradição, a tese modernista ganhou força a partir das publicações de Ernest Gellner e Benedict Anderson, em 1983, nas quais argumentam que as origens do nacionalismo europeu estariam relacionadas ao advento das sociedades modernas, momento no qual mudanças estruturais nas sociedades europeias seriam responsáveis por multiplicar a frequência das comunicações e contatos interpessoais, criando a possibilidade e a necessidade de ideais nacionalistas.

Durante certo tempo, os estudiosos das épocas pré-modernas agiram com muita cautela ao atribuir o termo nação às comunidades 
políticas anteriores à Modernidade. Em vez disso, acabaram por preferir expressões como "reinos e principados, cidades-estados, e impérios [...], tribos, paróquias, clãs e famílias" (SELTZER, 2005, p. 220, tradução nossa). No entanto, tal formulação foi insuficiente para outro grupo de estudiosos, que, lidando com manifestações de sentimento nacional muito semelhantes às da época moderna, contestaram as teses modernistas. É o caso de Susan Reynolds, que, ao estudar comunidades políticas medievais, argumenta que "a nação em si mesma é o produto da crença de seus membros de que ela existe" (REYNOLDS apud SELTZER, 2005, p. 220, tradução nossa).

Estudando documentos da época, a pesquisadora defende que o fato de pessoas compartilharem uma mesma lei e governo é suficiente para promover a solidariedade e as fazer se afirmar como um mesmo povo. Leiamos sua afirmação (REYNOLDS apud SELTZER, 2005, p. 221, tradução nossa):

[...] um dos mais importantes desenvolvimentos políticos dos séculos após 900 foi que, em muitas áreas, as lealdades da realeza acabavam por coincidir com as solidariedades de suposta linhagem comum e de lei. Reinos e povos acabavam por parecer idênticos - não invariavelmente, mas com suficiente frequência para a coincidência entre os dois parecer a norma para os contemporâneos.

De acordo com essa autora, o termo natio aparece em documentos medievais não apenas relacionado às comunidades de estudantes e professores dentro das universidades. Ele expande-se para além desse sentido, muitas vezes sendo usado como sinônimo de gens e populus e, portanto, encontrando sua melhor tradução no termo povo. É o que ela mostra citando uma definição de natio feita em 900 pelo canonista Regino Prumiensis, que é surpreendentemente parecida com a moderna: "As várias nações/povos [diversae nationes populorum] diferem-se na linhagem, língua e leis” (REYNOLDS apud SELTZER, 2005, p. 221, tradução nossa).

Entendemos que, nesse debate, a proposta feita anos antes pelo historiador francês Bernard Guenée (1981) continua válida e encontrar-se-á com a visão desta historiadora inglesa. Para esse autor, o primeiro indício da existência do sentimento nacional é a utilização de uma palavra para nomear uma comunidade. Ele afirma que na Antiguidade, por exemplo, o rio Reno separava a Gallia da Germania, porém, desde o início da Idade Média, novos termos surgiram do próprio povo. Os nomes dos povos no fim da Idade Média provam, por existirem, um "sentimento nacional elementar" e sustentam, traduzem e determinam, por sua própria natureza, "alguns mitos fundamentais da nação e do Estado que os possuem”.

Os rios foram substituídos pelas línguas na delimitação de uma nação. Nos séculos XIV e XV, embora não houvesse uma coincidência perfeita entre Estado, nação e língua, esse era o ideal a ser atingido na época, sendo a língua um elemento utilizado para distinguir um Estado do outro, formando estados nacionais. A utilização educativa e reformadora do vernáculo no mundo eslavo é um exemplo de como a língua torna-se um elemento agregador e delimitador. Denis (1985, p. 298) exprime a força que a língua eslava possuía na formação do sentimento nacional, em oposição a uma autoridade imposta pela língua latina:

Bem depressa a língua latina, veículo da cultura e aceite sem contestação pela nossa civilização ocidental, deveria ser rejeitada pelas nações eslavas: ela simbolizava, mercê da sua utilização generalizada, o aniquilamento das restantes civilizações. Para elas, a resistência à autoridade imposta, religiosa e política, a sobrevivência do património cultural já adquirido, passava pela salvaguarda da língua materna. Daí a importância e o êxito das correntes de pensamento, laico ou religioso, que 
compreenderam o facto e procederam para que, em matéria de educação, a língua materna fosse o fundamento de todo o conhecimento. Poder-se-á afirmar que o antigo esloveno continua a ser hoje o cimento entre todos os Eslavos.

A língua, contudo, não foi o único elemento agregador de uma nação. Também a religião e a história desses povos reuniram-se para a constituição do sentimento nacional. Com relação à primeira, está a religião cristã: sendo tão difundida na Europa, por que não formar uma grande nação cristã? E a resposta a essa questão são os santos, pois "o sentimento de uma nação se traduz, se torna preciso e se fortifica pela escolha de um santo protetor" (GUENÉE, 1981, p. 101). Diversos são os exemplos que mostram isso, como São Venceslau, na Boêmia, São Denis, na França, São Jorge, na Inglaterra, Estanislau, na Polônia, entre outros. Desde o século X, esse tipo de associação entre Estado e santo, como verificado na Boêmia, estava presente em todos os Estados no fim da Idade Média.

Com relação à história, afirma Guenée que, desde o século XII, diversos povos buscavam raizes mais antigas para justificar sua superioridade nacional. Apoiavam-se em personagens como Bruto e Artur, em tempos e lugares como Roma e Tróia. No caso tcheco, sabemos da história do Grande Pai Tcheco (Praotec Čech), fundador mítico do povo tcheco, sua filha Libuše, aquela que vislumbrou uma terra rica à soleira da montanha (prah, em tcheco, daí o nome da capital, Praha, de acordo com uma das interpretações tradicionais) e do rei Venceslau, que, de tão bondoso, era capaz de pedir esmolas pelos pobres. ${ }^{2}$ Esses mitos fundadores tchecos foram organizados por um cronista de nome Cosmas. Seu Chronica Bohemorum data do século XII e serviu de base para coletâneas de lendas tchecas, como o famoso trabalho do historiador Alois Jirásek, Staré pověsti české [Antigas lendas tchecas], de 1894.

2- Desde o século XI, ele é considerado governante eterno das terras tchecas.
Esse sentimento nacional, variável entre os países, exige uma diferenciação entre o nativo e o estrangeiro. Este último, vindo de outros lugares, deixou de ser alguém de outra senhoria, de outra justiça, de outra cidade para ser aquele que nasceu fora do reino. Acompanhado a isso, surgiu o sentimento de distinção das características de cada país e cada povo:

[...] onde a inveja dos judeus convivia com a perfídia dos persas, a sabedoria dos gregos, a gula dos gauleses, o orgulho dos francos, a cólera dos bretões, a crueldade dos hunos ou a deslealdade dos habitantes de Poitou (GUENÉE, 1981, p. 110).

Está na ordem dessas distinções o complexo antagonismo entre tchecos e alemães. Desde os remotos tempos do Império da Grande Morávia do século IX, comumente apontado por historiadores como a primeira grande unidade política eslava na região das atuais Eslováquia e República Tcheca, encontramos na bibliografia indícios desse antagonismo. Thomson (1945, p. 11), por exemplo, relata que, em 846, Luís, o Germânico, "subjugou a Morávia, mas sofreu uma derrota quando atacou os eslavos da Boêmia”. Sobre o século $\mathrm{X}$, findo o referido império e inaugurado o principado dos Přemyslidas, Čornej et al. (1992, p. 35) comentam a retaliação sofrida pelo então príncipe Václav quando, durante seu reinado (por volta de 907-935), teve de resistir a uma represália militar do saxão Heinrich der Finkler (Heinrich I da Germânia), após tomar para si o principado de Kouřím.

Scales (1999, p. 331) conta-nos acerca da enorme quantidade de colonos alemães que migraram para o reino da Boêmia a pedido dos primeiros Přemyslidas, seja como agricultores ou ingressando nas cortes reais, seja compondo grande parte da classe de comerciantes urbanos ou, ainda, fundando cidades inteiramente alemãs.

Tudo isso sem contar com os quase trezentos anos de dominação austríaca sobre Boêmia e Morávia - da batalha de Bilá Hora em 
1620 à fundação do Estado da Tchecoslováquia em 1918 - e o período do Protetorado (1938 - 1945), quando Boêmia e Morávia estavam sob a influência direta do Terceiro Reich. Nas palavras de Thomson (1945, p. 14):

[...] se esse conflito entre eslavos e teutônicos é realmente a chave para toda a história tcheca, ou não, pode ser discutível, mas não há dúvidas de que houve muitos períodos da história tcheca em que esse antagonismo racial foi a questão primordial.

Isso remete-nos à leitura de Scales (1999), ao mostrar que as expressões tchecos e alemães não só invocavam um conjunto de pré-noções firmemente estabelecidas já no século XIV, mas também estavam fundamentalmente relacionadas com a ideia de nação. A pergunta que o autor se faz é se é possível, na análise dos textos de época, encontrar pistas sobre a autoconsciência daqueles colonos alemães e seus descendentes: eles se consideravam alemães, tchecos, uma comunidade à parte das duas nacionalidades, ou então absolutamente não se consideravam uma comunidade? A esse respeito, diz o autor:

Em resumo, parece bastante razoável supor que esses colonos devem ter seguido um caminho de não forjar uma ideia separada de solidariedade, mas sim de emprestar seu apoio à noção mais ampla de comunidade "Boêmia" centralizada na monarquia, da qual seu bem-estar depende em grau significante. (SCALES, 1999, p. 333, tradução nossa).

Como esses Bohemian Germans [alemães da Boêmia] receberam apoio da monarquia para lá chegarem e para lá continuarem, era de se esperar que se sentissem integrados aos tchecos. Mas não é isso que a leitura dos documentos da época mostrou. Lendo a crônica de Peter von Zittau, abade do mosteiro de Zbraslav no século XIV e reconhecido como o autor da Crônica de Zbraslav (conhecida também como
Crônica de Köningsaal, nome alemão da região onde se encontra o mosteiro), Scales identifica a dificuldade do autor em se referir a esse grupo intermediário entre alemães e tchecos.

0 próprio Peter era um desses colonos alemães na Boêmia e se considerava um boêmio, leal ao Reino da Boêmia, e opositor às tentativas de ingerência externa praticadas pelos reinos alemães. Em sua crônica, escreveu que "os boêmios eram o seu povo, seu gens” (SCALES, 1999, p. 336, tradução nossa). No entanto, à primeira vista integrado à comunidade do reino, Peter von Zittau acaba por denunciar a ausência da integração completa dos alemães da Boêmia. Comentando a preocupação da rainha tcheca Guta Minsterberská em fazer justiça igualmente a todos seus súditos, o cronista afirma: "os tchecos (Bohemi) [...] mantêm antigas rixas (rixae veleres) contra a população alemã (Theutonici)" (SCALES, 1999, p. 337, tradução nossa).

Nesse ponto, Scales chama a nossa atenção para a ausência de um termo específico em referência aos alemães da Boêmia: eles são simplesmente alemães (Theutonici). Afırma o autor:

[...] a medida material da etnia é a língua: gens e linguagium são usadas aqui intercambiavelmente. A ideia de a preponderância da língua tcheca ("boêmia") ser o elemento fundamental em ser boêmio não era incomum nos escritos relacionados às terras da Boêmia; para citar apenas um famoso exemplo, o imperador Karel IV - que, como filho de uma mãe Přemyslida, tinha o direito fundamental de ser considerado um Bohemus - recorda em sua Autobiografia como, retornando à Boêmia como um jovem homem, reaprendeu o tcheco de sua infância até o ponto de falar "igual a outro Boêmio". (SCALES, 1999, p. 337-338, tradução nossa)

Esse é um dos principais motivos que levaram Scales a concluir que os alemães da Boêmia encontravam-se "à margem da comu- 
nidade": leais súditos dos monarcas tchecos, todavia não estavam completamente mesclados com os tchecos sob a identidade boêmia. Sendo o fator classificatório predominante o idioma, os alemães da Boêmia do século XIV encontravam-se numa posição bastante ambígua, sem se considerar como um grupo à parte (vistas as diferenças, inclusive linguísticas, de suas origens alemãs), nem alemães plenos (pois eram súditos dos tchecos) e nem tchecos plenos (pois eram de natio-gens-linguagium diferentes).

Essa diferenciação não ocorria apenas entre tchecos e alemães. Kolbuszewski (1939) apontava, já no final da década de 1930, para a desconfiança que os poloneses tinham dos tchecos durante a Idade Média, em função de sua proximidade com os alemães. 0 que, em um primeiro momento, pode parecer contraditório ao que Scales mais recentemente propôs, na verdade, é uma informação que apenas sustenta a posição em que os tchecos estavam, no final desse período, constituindo-se como um grupo delimitado e diferenciado dos não-tchecos. Tanto isso ocorreu que seus vizinhos muito mais próximos linguisticamente (o polonês e o tcheco são línguas um tanto próximas) sentiam-se diferentes e desconfiados.

Seltzer (2005) segue no mesmo caminho da coincidência entre os termos natio, gens e linguagium, na análise do posicionamento político-religioso da classe burguesa tcheca entre os séculos XV e XIV. Para tanto, analisa o conteúdo de Staré letopisy české, uma coleção de crônicas escritas por autores anônimos entre 1430 e 1530, que são frequentemente usadas como fonte primária pelos historiadores do hussitismo ${ }^{3}$ e da Igreja Utraquista ${ }^{4}$.

0 autor sustenta que um dos objetivos dos autores das crônicas contidas em Staré letopisy české, em sua maioria burgueses utraquistas de Praga, era ajudar a propagar as reformas por

3- Termo genérico posteriormente atribuído aos movimentos religiosos de caráter reformista nas terras históricas tchecas, especialmente nos séculos XV e XVI.

4- Igreja de caráter nacional tcheca que se tornou oficial no século $\mathrm{XV}$. Inicia-se como um dos grupos hussitas do período que ofereciam a comunhão em duas espécies para os leigos. meio de sua escrita. No entanto, Seltzer (2005) ressalta que os motivos pelos quais as pessoas apoiavam, ou não, os hussitas eram os mais variados possíveis, muitas vezes sendo pouquíssimo relacionados com motivações teológicas, complexas demais para a grande maioria dos habitantes do reino. Portanto, para cumprir seu objetivo, os autores de Staré letopisy české procuraram unir todos os tchecos sob uma causa nacionalista. Essa solução, consciente ou não para os escritores tchecos, sustentava-se, pois mostrava que "um determinado grupo linguístico poderia ter um destino coletivo" (SELZER, 2005 , p. 207, tradução nossa), ao conectar a nacionalidade à força do fervor religioso. E, para os escritores, tal procedimento consistia em figurar os estrangeiros:

[...] como sendo traiçoeiros, pérfidos e bárbaros, de modo a fazer um apelo a todos os tchecos, mesmo àqueles que rejeitavam o utraquismo, impelindo-os a colocar sua origem étnica à frente dos outros laços para o bem-estar geral de toda a nação tcheca.

No entanto, como distinguir os tchecos dos não-tchecos? Num momento em que tchecos e estrangeiros, principalmente alemães, vivam lado a lado nas cidades e cortes da Boêmia e numa época na qual as questões a respeito da identidade nacional eram completamente desconhecidas para a maioria das pessoas, o idioma mostrou-se um dos elementos fundamentais de diferenciação. Seltzer (2005) evidencia que língua e nação estão tão intimamente conectadas que foram inclusive usadas como sinônimos na Boêmia do final da Idade Média. 0 autor toma como exemplo uma frase escrita pelo autor do texto Staré letopisy české para mostrar a polissemia do termo tcheco jazyk naquele tempo. De acordo com a citação de Seltzer (2005, p. 228-229, tradução nossa), o autor do texto, buscando sensibilizar seus leitores para que continuassem sua obra, faz um apelo a "alguma pessoa, para a 
qual o bem-estar geral da nação tcheca [jazyka českého] é fundamental". 0 historiador explica:

Jazyk, em tcheco moderno, significa idioma ou língua, o que também significava em tcheco arcaico. Mas, pelo menos desde o início do século XIV, jazyk também se referia a todas as pessoas que falavam um idioma e tinham um território específico em comum. A expressão moderna para "nação", národ, algumas vezes significando também "raça” ou "povo", é semanticamente muito próxima ao natio latino, derivando, como essa última expressão faz, do verbo narodit, “nascer”. [...] Národ e jazyk são algumas vezes usados como sinônimos a partir do século XV [...]. (SELTZER, 2005, p. 228-229, tradução nossa).

Assim sendo, Seltzer (2005) diz que, até a metade do século XVI, quando o termo národ começa a ser usado nos escritos em tcheco, jazyk era o termo dominantemente usado como tradução de natio/gens e língua. 0 autor completa:

Nesse sentido, existe uma clara conexão em tcheco entre as ideais de "nação" (ou "povo") e "língua", conexão que era invocada especificamente para excluir aquelas pessoas, principalmente os alemães, que viviam na Boêmia, mas não falavam tcheco. (SELTZER, 2005, p. 229, tradução nossa)

Ao considerarmos essa coincidência semântica, podemos enxergar como seria possível a imaginação de comunidades nacionais no final da Idade Média. Na Boêmia do século XV, falar tcheco era um elemento essencial para ser tcheco.

\section{Universidade de Praga efetivamente nacionalizada}

A coincidência medieval entre os termos jazyk e národ não gera polêmica apenas entre os estudiosos da atualidade. Ela também está nas entrelinhas de um famoso episódio da história tcheca que, não por acaso, consistiu em uma disputa entre nacionalidades. Trata-se da nacionalização da Universidade de Praga, a partir do Decreto de Kutná Hora.

Durante o governo de Carlos IV [Karel IV em tcheco], no século XIV, Praga tornou-se capital do Sacro Império Romano-Germânico. Um conjunto de intervenções urbanísticas, econômicas, legais e culturais foi conduzido por um imperador internacional, que passou sua infância em Paris e, ao voltar à sua cidade natal, investiu em fazer dela algo que hoje chamaríamos de uma cidade cosmopolita.

Como imperador, ele institui uma Bula de Ouro (1356) na qual coloca o rei da Boêmia em destaque nos eventos do Sacro Império, deixa as terras tchecas legalmente administradas somente por tchecos, bem como estabelece que os habitantes da Boêmia só pode ser julgados pelos seus conterrâneos. Além disso, ele fortalece o arcebispado de Praga, dando-lhe a incumbência de coroar o rei da Boêmia (TANNER et al., 1968, p. 161 e seguintes).

Mas uma de suas atuações, a mais relevante para este artigo, foi a fundação da primeira universidade nacional em 1348, para a qual convidou professores tchecos, alemães e poloneses, entre outros. Praga passou a atrair estudantes de várias regiões do império. A Universidade de Praga foi fundada seguindo o modelo da Universidade de Paris (Confira: LE GOFF, 2003, p. 102 e p. 178; SPINKA, 1968, p. 25 e p. 96-98). Seus alunos e professores eram organizados em quatro grupos, denominados nações: poderiam pertencer à nação bávara, saxônica, polonesa ou boêmia. 0 objetivo dessa organização era facilitar a tomada de decisões do Conselho, ordenando o corpo acadêmico nesses quatro grupos e oferecendo-lhes um voto cada. Assim sendo, os integrantes de cada nação deveriam articular-se de modo a conseguirem decidir os votos.

Sua carta de fundação registra um discurso real de valorização dos tchecos. Lembremos que as universidades, até então, não 
haviam sido instituídas pelos magistrados, mas surgiram das corporações de ofício, com seus mestres e estudantes. Na carta de fundação, originalmente escrita em latim, o imperador e rei tcheco propõe uma universidade para os tchecos, sem que eles precisem ir a países estrangeiros para buscarem o saber, como vemos neste recorte:

Deus se alegra da abundância natural de cultura em nossa terra, que vemos, em nossos dias, [e que] foi condecorada com um grande número de homens instruídos. E, assim, para que os nossos habitantes fiéis tchecos, incessantemente famintos pelos frutos do conhecimento, não precisem ir a países estrangeiros pedir esmolas, mas possam encontrar no reino uma mesa preparada para as refeições... (KAREL IV, 1348, tradução nossa a partir da versão tcheca).

Mas essa universidade nacional não era tão tcheca assim. A questão mais problemática é o fato de que a divisão em nações acabava empoderando professores e alunos de origens alemãs, de número bem maior que aquele dos de outra origem, nos primeiros anos da universidade. Teoricamente, estariam divididos em duas nações, bávara e saxônica, o que lhes rendia dois votos, contrabalanceados pelos dois votos das nações eslavas. No entanto, os alemães eram também a maioria dentro da nação polonesa e, além disso, estavam também muito presentes na nação boêmia. Assim, eles acabavam tendo, na prática, três votos no Conselho da Universidade, além de poderem influenciar o quarto voto.

Nas primeiras décadas a partir de sua fundação, os alemães compunham a maioria dos integrantes da universidade. No entanto, cinquenta anos depois, a situação tinha se alterado e os tchecos os superaram em quantidade. Porém, a maioria numérica não lhes rendia poder de fato. Essa questão acabou, por fim, engendrando uma disputa entre nacionalidades universitárias, a qual, como veremos, ampliar-se-á para além do âmbito daquela instituição.

No início do século XV, circulavam pela Europa os escritos do clérigo inglês John Wycliff. Alcançando a boêmia, as ideias desse severo crítico do poder clerical tiveram grande recepção entre os mestres tchecos da universidade, adeptos à filosofia realista, mas sofreram forte oposição dos alemães, ligados à filosofia nominalista, fortalecendo a disputa entre as nações. É o que evidencia uma frase de Jan Hus, professor da Universidade de Praga, escrita nas margens de um manuscrito de Wycliff, que ele copiava: "ha ha, alemães, ha ha, fora fora" (SELTZER, 2005, p. 232, tradução nossa).

Tal situação fez com que os tchecos da universidade buscassem ajuda política. E o momento era bastante oportuno para isso. Naquele tempo, Venceslau IV [Václav IV em tcheco], rei da Boêmia e antigo imperador do Sacro Império Romano, deposto em 1400 por Ruprecht, eleitor do Palatinado, buscava o apoio da Universidade para abandonar o papa de Roma, apoiador de seu rival, durante os eventos do Concílio de Pisa, incumbido de resolver o cisma papal. Em 1409, havia dois papas, um estabelecido em Avignon e outro em Roma, um excomungando ao outro e defendendo ser o único verdadeiro. Se Venceslau participasse na resolução desse cisma, poderia ganhar certo capital político.

Como os alemães da universidade negaram o apoio, Venceslau IV e os tchecos firmaram um acordo: em troca do apoio durante o Concílio, os tchecos receberiam o comando da universidade. Tal acordo foi formalizado no documento que ficou conhecido como Decreto de Kutná Hora (1409), segundo o qual a nação boêmia teria o direito a três votos, enquanto as outras três nações votariam em conjunto sob um único voto.

0 que mais nos chama a atenção nesse caso é a forma como foi redigido o texto do Decreto. Conta-nos Seltzer (2005, p. 233) que o texto inicia com a afirmação de que o rei tcheco, apesar de responsável pelo interesse de todos os 
súditos deve, de acordo com o direito natural, cuidar principalmente das necessidades do povo de sua origem. A partir disso, o texto critica a proeminência da nação alemã [nacio Theutonica] dentro da universidade, acusando-os de usurpar o controle dos herdeiros por direito do Reino, "a nação tcheca [nacioque Boemica, eiusdem regni iusta heres]". Assim:

[...] considerando esse degradante estado das coisas, o rei move-se imediatamente para consertar essa situação, dando à 'nacio Boemica' os três votos originalmente possuídos pela 'nacio Theutonica'. (SELTZER, 2005, p. 233, tradução nossa)

0 documento surpreende pela interpretação que dá à situação dentro da Universidade de Praga. Formalmente, as nações do Conselho não se baseavam em critérios como idioma - afinal, a língua franca da universidade era o latim - mas simplesmente nas referências geográficas dos integrantes. No entanto, a questão é posta no texto como sendo uma diferença entre nacionalidades: a justiça só seria alcançada se os tchecos recebessem os três votos usurpados pelos alemães.

Os alemães da universidade reagiram prontamente a essa mudança nas regras. No fim, vendo que seus protestos eram inúteis, decidiram por abandonar em massa a Universidade de Praga. Muitos dos mestres e alunos acabavam fundando a Universidade de Leipzig, enquanto alguns outros se mudaram para outras universidades, sendo uma delas a Universidade de Viena. Os antigos mestres alemães da Universidade de Praga acabariam por se tornar alguns dos mais implacáveis inimigos dos hussitas nos anos seguintes.

Com o Decreto de Kutná Hora, a Universidade de Praga tornou-se efetivamente nacional, aqui, tcheca. Quando direcionamos nosso olhar para dois sujeitos em dois diferentes episódios, confırmamos essa mudança. 0 primeiro é o professor e clérigo Jan Hus. Conhecido pregador e educador (AGUIAR, 2012), famoso na história das religiões por suas posições reformistas antes da Reforma Protestante, ele esteve presente em Kutná Hora para debater com o então reitor da universidade, Henning de Baltenhagen, a questão da posição que a instituição defenderia oficialmente diante do Cisma. 0 reitor, alemão, defendia o papa romano, enquanto Hus, tcheco, defendia a neutralidade.

Essa oposição tornou-se pública $\mathrm{e}$ Baltenhagen acusou Hus de heresia, fazendo com que o então arcebispo de Praga, Zbyněk, se posicionasse contrário ao clérigo tcheco. De acordo com Oberg (1971), apesar do apoio real obtido pelo decreto de Kutná Hora, e da consequente posição de reitor da universidade que Hus obteve após o decreto, essa acusação de heresia manteve-se e, podemos dizer, intensificou-se, ao longo dos anos, tornando impossivel um resultado diferente no Concílio de Constança. Afırma o autor (OBERG, 1971, p. 46) que "os fatos relacionados com os dias de Kutna Hora revelam influências políticas e morais fortes que iriam pesar seriamente na condenação de Hus". Este foi condenado à fogueira pelo concílio e morto em 6 de julho de 1415 .

0 segundo é Jerônimo de Praga [Jeroným Pražský em tcheco], também presente à reunião de Kutna Hora. Esse clérigo, mestre da Universidade de Praga e colega de Jan Hus, diferenciava-se daquele por ser "um reformador de tipo incendiário, ou agitador popular" (BERNARD, 1958, p. 5, tradução nossa) e que se preocupava em espalhar as ideias reformistas para além da Boêmia. Os documentos a seu respeito são mais escassos do que os hoje existentes sobre Hus.

Durante a estadia de Jerônimo em Viena, ele, cujo "entusiasmo invariavelmente prevalecia sobre a discrição" (BERNARD, 1958, p. 5), é relatado pregando as ideias reformistas. No entanto, o momento não era dos mais propícios, visto que a cidade passara anos antes por turbulências sociais: sob a liderança da universidade, que radicalizou uma posição conservadora após alguns de seus membros terem sidos acusados de wycliffısmo, as autoridades locais estavam reprimindo qualquer 
tipo de nova agitação. Assim sendo, Jerônimo acaba sendo preso.

Ali, ele foi julgado. Bernard (1958) aponta que as acusações gradualmente deixam de ser por sua adesão às ideias heréticas de Wycliff e pelas agitações em outras cidades e passam a ser a sua participação nas contendas que resultaram no Decreto de Kutná Hora:

Quando, mais tarde, Jerônimo censurou [Johann] Butzbach, dizendo que aquele ato [de lhe apontar o dedo durante uma de suas palestras] não era compatível com o amor cristão, Butzbach respondeu que o próprio Jerônimo exibiu uma acentuada falta de amor cristão ao fazer parte do quodlibet que precedeu o Decreto de Kutná Hora. Essa história deixa bastante claro que os inimigos mais irreconciliáveis de Jerônimo em Viena eram os professores alemães que deixaram Praga em 1409, e é ainda provável que foram eles os responsáveis por sua denúncia ao Official [Grippenperk]. (BERNARD, 1958, p. 7).

Após uma primeira fase do julgamento, a qual se baseava nas acusações feitas pelo promotor e nas defesas de Jerônimo, o julgamento foi adiado para os dias seguintes. Visto que as autoridades temiam uma fuga do clérigo, este foi obrigado a jurar, sob pena de excomunhão, que ficaria na cidade durante todo o julgamento. No entanto, quando este foi retomado, seguiu para o depoimento de quinze testemunhas de acusação, "quase todas as testemunhas sendo alemães ou austríacos que deixaram a Praga em 1409 [...]" (BERNARD, 1958, p. 9). Observando que o julgamento caminhava para uma inerente condenação, durante essa sequência de testemunhos, Jerônimo foge da cidade de Viena. Nas palavras de Bernard (1958, p. 8):

Como quase todas as testemunhas foram adversamente afetadas pelas consequências do Decreto e sendo a corte obviamente simpática aos pontos de vista dessas testemunhas, só poderia haver um único veredito: Jerônimo seria condenado como herege, como vingança por Kutná Hora.

No final das contas, o clérigo acabaria, cinco anos depois, preso, condenado e queimado na fogueira, do Concílio de Constança, em 1416, assim como o fora seu mestre, Jan Hus, no ano anterior. É claro que não podemos dizer que o Decreto de Kutná Hora seja a causa única e imediata da morte de Hus e Jerônimo, mas fica visível que o calor de uma disputa envolvida por um sentimento nacional alimentou a fogueira que os queimou. E esse calor só aumentou com o passar dos anos.

\section{Formação de um projeto de educação: língua, religião e nação}

Com a morte de Hus e Jerônimo, uma grande revolta toma conta de seus partidários, que, em poucos anos, já formaram exércitos em busca de uma terra prometida, cada vez mais afastados da Cúria Romana. Ambos foram queimados em terras alemãs. Isso só fortaleceu aquele grupo de professores tchecos que queriam uma universidade nacional. Progressivamente, ao longo do século $\mathrm{XV}$, as negociações políticas e religiosas, levadas a cabo tanto pelos representantes da universidade quanto pelos clérigos que se diziam seguidores de Hus, passam a assumir de forma cada vez mais forte um teor nacionalista. Essa identidade nacional tcheca assume um teor de autovalorização religiosa em oposição aos alemães. Ser um verdadeiro fiel e um verdadeiro tcheco era a mesma coisa (SELTZER, 2005, p. 268, tradução nossa).

Em 1420, dois grupos hussitas tradicionalmente conhecidos como utraquistas e taboritas chegaram a um acordo para tentar superar suas diferenças. Conhecido como "Quatro artigos de Praga", esse documento definia os princípios religiosos básicos que compartilhavam os diferentes grupos hussitas. 0 historiador Howard Kaminsky, citado por 
Atwood (2009, p. 94, tradução nossa) traz-nos os pontos desse acordo:

1. Nós apoiamos a ministração do corpo e do sangue do senhor aos leigos nas duas espécies, pois [...] essa foi a instituição do Cristo e [...] dos primeiros apóstolos e da Igreja Primitiva [...], como o Concílio de Constança nos permitiu.

2. Nós apoiamos a adequada e livre pregação da palavra de Deus e de toda a sua verdade.

3. Todos os clérigos, do papa para baixo, deveriam desistir de sua pompa, avareza e propriedade inadequada na superfluidade sobre os bens temporais e eles deveriam servir como um modelo vivo para nós.

4. Nós apoiamos a purgação e a cessação de todos os pecados mortais públicos de cada um em sua própria pessoa. E apoiamos a limpeza do reino e da nação da Boêmia de toda a falsa e maligna calúnia e, nesse sentido, apoiamos o bem comum de nossa terra.

Esses pontos foram utilizados ao longo dos anos seguintes como fundamentos das negociações das igrejas tchecas com a Igreja de Roma. No Concílio de Basileia (1433), o primeiro destes artigos foi aprovado, embora tenha sido seguido apenas pelos grupos hussitas e nunca pela Igreja, conforme explica Atwood (2009, p. 94, tradução nossa):

Os artigos 2 e 3 mais claramente refletem o movimento de pobreza apostólica que era o ensino central da União dos Irmãos. 0 mais controverso dos quatro artigos provou ser o quarto, que convocava os fiéis para purgar a Boêmia do pecado e da falsidade. Isso não foi muito tempo antes de Žižka tomar esta tarefa para si.

A União dos Irmãos, ao qual o autor se refere, é o grupo religioso formado com inspiração nas ideias de Petr Chelčický, que, na geração seguinte à de Jan Hus, opôs-se à divisão tripartite da sociedade medieval e propôs o pacifismo como prática de vida diária. Sua proposta pacifista era diretamente oposta à atuação de Jan Žižka, guerreiro taborita que liderou os exércitos tchecos contra as cruzadas enviadas à Boêmia antes do Concílio de Basileia (AGUIAR, 2015). É nesse grupo que, cerca de um século e meio depois, surgirá o educador Jan Amos Comenius.

Analisando os artigos, percebemos que não apenas as questões da comunhão em duas espécies, da liberdade de pregação e da pobreza do clero estavam presentes nos primórdios dos movimentos hussitas do início do século XV. Havia também uma questão nacionalista, fortemente presente no quarto artigo. A questão religiosa estava indissociada da questão nacional e esta da língua. Só é possível compreendermos o debate religioso, bem como as ações educacionais nele envolvidas, se a esses agregarmos, no caso tcheco, um ideal nacionalista. Portal (1968, p. 13-14) afirma que:

Maior importância teve a agitação da Reforma, da qual a heresia hussita foi, a partir do séc. XV, a primeira manifestação. Movimento de revolta social e nacional, sem dúvida, mas de essência religiosa, e que transbordou para os países vizinhos, sobretudo para a Polónia, o hussitismo marcou duradouramente a mentalidade do povo tcheco.

Atentemos para a proposta do historiador francês de considerar o hussitismo como um movimento social e nacional de essência religiosa, que marcou a mentalidade do povo tcheco. 0 que aconteceu no século $\mathrm{XV}$, e se estendeu por pelo menos mais um século entre os tchecos, deixou marcas na história desse povo e no seu modo de agir e de pensar que persistem até os dias de hoje, se não como ação consciente no mundo, pelo menos como mito fundador. Esse movimento "social e nacional de essência religiosa” constituiu um 
ideal de tchequidade ${ }^{5}$, do jeito tcheco de ser e agir no mundo.

Nicolau Sevcenko, em seu prefácio às cartas do então futuro presidente da República Tcheca, Václav Havel, escritas da prisão na década de 1970, mostra o lugar desse movimento na formação da imagem de firmeza e esperança para os tchecos nos momentos difíceis de sua história:

Num dos momentos mais prostrantes de seu longo aprisionamento, quando já sentia faltarem-lhe as forças, Václav Havel recebeu uma imagem de um amigo artista que lhe fez inflamar o coração e recobrar o ânimo. Era um retrato de Comenius chorando por Praga. (SEVCENKO, 1992, p. 11)

A figura que consola o futuro primeiro presidente da República Tcheca no final do século XX é Comenius, o herdeiro dessa tradição hussita e nacionalista, que, no início do século XVII, propôs do exílio uma reforma das coisas humanas (incluindo nessa reforma um método de ensino) e que chora por sua nação tomada pelos alemães. 0 período aproximadamente entre os séculos XV e XVI foi uma Idade de Ouro, uma época na qual ser tcheco era motivo de orgulho.

Foi um período de passageira autonomia de um povo que, desde cedo, conheceu o domínio estrangeiro (PORTAL, 1968, p. 14). Reside nessa passageira autonomia seu desenvolvimento econômico, religioso e cultural. A coincidência dessa autonomia com o movimento hussita não é por acaso e começa com o que Portal chama de um "despertar glorioso" no "seio de complexos políticos" (PORTAL, 1968, p. 15), com as reformas de Carlos IV na Boêmia. A Universidade de Praga, como vimos, possui importante papel nesse processo. Mas o significado dessa autonomia tcheca só é possível de ser compreendido se confrontado

5- Expressão que utilizamos inicialmente em Aguiar (2012, p. 314), a partir da palavra češství utilizada pelo historiador tcheco Václav Flajšhans, como tradução à sua fala, publicada no jornal Národní Listy em 1915: "Hus é, simplesmente, o símbolo de nossa tchequidade na sua mais bela abrangência." com o convívio secular entre tchecos e alemães. Portal (1968, p. 90) confirma-nos que a autonomia tcheca se constrói em oposição à grande presença de alemães naquelas terras.

De certo modo, o período que esse historiador chama de Idade de Ouro da Boêmia, com suas minas de prata (especialmente em Kutná Hora), vinhas, crescimento do comércio, o início da escrita literária em tcheco, além das já citadas ações de Carlos IV, é um período de fortalecimento da tchequidade. Além disso, o Decreto de Kutná Hora assume um lugar central no início desse período.

Voltando a Jan Hus, percebemos que sua pregação presencial na Capela de Belém (14021412) e sua escrita de cartas (prioritariamente entre 1412-1415), ícones de seu trabalho educativo, bem como sua atuação na Universidade de Praga são atuações formativas da identidade tcheca nesse contexto descrito por Portal (1968), que afirma:

Sob a administração de João Hus, a Universidade de Praga fica debaixo da vigilância da "nação" (comunidade de estudantes) tcheca, que até então tinha de inclinar-se perante três outras "nações" estrangeiras, a alemã, a saxónia e a polaca (decreto real de Kutná-Hora, 1409). Claro que o latim permanece a língua da universidade, e foi em latim que João Hus redigiu uma parte de suas obras. Mas as mais comoventes, sobretudo essas admiráveis Cartas aos Tchecos fiéis, saídas do fundo da prisão de Constança na véspera de sua execução, são escritas na língua nacional, língua cujo emprego João Hus se esforçara por desenvolver em todos os actos da vida pública. Aliás, é a ele que devemos as primeiras simplificações da ortografia tão características do tcheco. (PORTAL, 1968, p. 96).

Hus possui um papel decisivo no desenvolvimento da língua tcheca e desse nacionalismo que crescia desde o século XIV. É ele quem escreve a primeira cartilha para o 
ensino das primeiras letras, no início do século XV (MANACORDA, 2010, p. 238; AGUIAR, 2012, p. 108-113), para darmos um exemplo além dos já trazidos na citação acima. Sua morte fortaleceu o que o historiador francês chamou de consciência nacional tcheca. Esta, porém, não envolve apenas uma identidade nacional, um patriotismo. Ela envolve um sentimento de universalidade cristã e um conjunto de práticas formativas, como comunhão em duas espécies, o fortalecimento da língua tcheca, a instituição de formas de vida comunitária, como no caso de Chelčický, e a fundação de escolas de instrução popular, como podemos apreender a partir de Portal (1968, p. 100).

Os nomes dos personagens envoltos nas guerras hussitas ou no desenvolvimento dos Utraquistas e dos Taboritas, bem como dos Irmãos Morávios, marcam a história tcheca de tal maneira que eles se tornam personagens quase míticos. De certo modo, eles resgatam o mito fundador do Praotec Čech. Educação, língua, memória compartilhada e sentimento nacional constituíram o que aqui, tomando o termo por analogia, chamamos de paideia tcheca, a formação de uma tchequidade que, conforme afirmamos, está presente ainda hoje naquelas terras da Europa Central.

\section{Reflexões finais}

Percorremos este longo caminho, que começou com a discussão da possibilidade de se utilizar o termo nação no século XV, dirigindo nosso olhar para o caso das terras históricas tchecas, o que nos pareceu uma utilização coerente. Seguimos para a análise de um episódio central para o estabelecimento do início do nacionalismo tcheco, que se construiu em oposição à presença dos alemães: a nacionalização da Universidade de Praga em 1409 e suas consequências na história de dois sujeitos. Por fim, estabelecemos as ligações desse nacionalismo com o movimento religioso hussita na formação de uma tchequidade com suas consequências culturais, linguísticas e educacionais.
Por meio desse caminho, apontamos a necessária associação entre educação e nacionalismo na Boêmia do século XV. Os clérigos, os cronistas, a universidade, os textos, a cartilha de Jan Hus e mesmo as escolas tchecas foram os agentes de constituição e transmissão da tchequidade que aqui trouxemos.

Há cerca de um século e meio, Comenius está presente no meio desse caldo cultural, linguístico, religioso e nacionalista. Como essa tchequidade chega até ele é algo para ser desenvolvido em outro artigo. Lembremos apenas que suas primeiras reflexões, além de parte importante de seus escritos posteriores, são escritas em tcheco e para os tchecos. Um evento histórico narrado por Kulesza (1992, p. 50) serve como um indício para vermos a presença desse nacionalismo em Comenius e sua permanência nos séculos posteriores:

Em meados do século XIX, Comenius torna-se representante de uma educação nacional e democrática, sendo reeditadas suas obras em checo, aquelas em latim sendo traduzidas para o vernáculo e publicados os manuscritos inéditos, como a Didática checa. No tricentenário de seu nascimento, o ministro austríaco Gautsch proíbe que a data seja considerada feriado nas escolas checas. Essa proibição foi decorrente de uma ordem do imperador Francisco José a partir do exame de um exemplar da Lux in tenebris e da percepção de seu forte sentido nacionalista. Porém, no dia 28 de março de 1892, uma multidão de patriotas, liderada pelo professor Masaryk, promove intensa manifestação ostentando o retrato do mestre. Masaryk, que viria a ser o primeiro presidente da Checoslováquia independente, ao findar a Primeira Guerra Mundial, quando de seu exílio na Holanda, toma para si o testemunho de Comenius, inspirando-se nele para conduzir a luta pela independência, como ele mesmo reconhece em seu livro Svetová Revoluce (Revolução Mundial), publicado 
em 1925. Assim, o nome de Masaryk fica definitivamente associado ao de Huss e Comenius na cultura nacional checa.

Mas esta é uma ligação que apontamos para desenvolvimentos futuros. Terminemos nosso artigo com um retorno ao início do século XIV. Um texto conhecido como Crônica de Dalimil é tido como um dos mais antigos escritos em língua tcheca conservados até nossos dias. Essa crônica reconta a história da Boêmia e constantemente descreve os alemães como o oposto negativo dos tchecos. Em um dos episódios mais famosos da crônica, o duque Oldřich, ao justificar por que havia escolhido uma camponesa tcheca como esposa em vez de outra que era nobre, afirma:
Raději sě chci s českú sedlkú snieti než ciesařovnu německú za ženu jmieti [...] Němkyně bude německú čeled mieti a německy bude učiti mé dèti.

A proto bude jazyka rozdělenie a ihned země zkaženie.

(SCALES, 1999, p. 2120).

Antes desposar uma tcheca camponesa do que uma imperatriz alemã com certeza [...] Uma alemã tem seus criados alemães E o alemão para meus filhos nas lições Isso causará a ruptura da nação [jazyk, que também pode ser língua]

E em nossa terra logo a depravação (tradução nossa).

\section{Referências}

AGUIAR, Thiago Borges de. Jan Hus: cartas de um educador e seu legado imortal. São Paulo: Annablume, 2012.

AGUIAR, Thiago Borges de. 'Minor' educator before Comenius: Petr Chelčický's pacifism. Acta Scientiarum.Education, v. 37, n. 1 , p. 35-46, 2015.

ATWO0D, Craig D. The theology of the Czech Brethren from Hus to Comenius. Park: The Pennsylvania State University Press, 2009. BERNARD, Paul. Jerome of Prague, Austria and the Hussites. Church History, v. 27, n. 1, p. 3-22, 1958.

ČORNEJ, Petr et al. Dějiny zemí koruny české: od příchodu slovanů do roku 1740. v. 1. Praga: Paseka, 1992.

DENIS, Marcelle. Ensino e pedagogia no mundo eslavo. In: MIALARET, Gaston; VIAL, Jean (Dir.). História mundial da educação, v. 2. Porto: Rés, 1985. p. 65-82.

GUENÉE, Bernard. 0 ocidente nos séculos XIV e XV: os estados. São Paulo: Livraria Pioneira: Edusp, 1981.

JAEGER, Werner. Paideia: a formação do homem grego. 4. ed. São Paulo: Martins Fontes, 2001.

KAREL IV [Carlos IV]. Zakládací listina Univerzity Karlovy v Praze ze 7. Dubna 1348. Praga, 1348. Disponível em: <http://www. cuni.cz/UK-1391.html>. Acesso em: 4 out. 2012.

KOLBUSZEWSKI, Stanisław. Influences of Czech culture in Poland in the middle ages. The Slavonic and East European Review, v. 18, n. 52, p. 155-169, 1939.

KULESZA, Wojciech A. Comenius: a persistência da utopia em educação. Campinas: Unicamp, 1992.

LE GOFF, Jacques. Os intelectuais na Idade Média. Rio de Janeiro: José Olympio, 2003.

MANACORDA, Mario Alighiero. História da educação: da antiguidade aos nossos dias. 13. ed. São Paulo: Cortez, 2010. 
OBERG, Renato Emir. Kutna Hora: influências morais e políticas no julgamento do mestre João Hus. Revista de História, São Paulo, n. 85, p. 33-47, mar. 1971.

PORTAL, Roger. Os eslavos. Lisboa; Rio de Janeiro: Cosmos, 1968.

SCALES, Leonard. At the margin of community: Germans in pre-Hussite Bohemia. Transactions of the Royal Historical Society, v. 9, p. 327-352, 1999.

SELTZER, Joel Daniel. Framing faith, forging a nation: czech vernacular historiography and the Bohemian Reformation, 14301530. 2005. 309 f. Tese (Doutorado em Filosofia) - Faculty of the Graduate School, Yale University, Yale, 2005.

SEVCENKO, Nicolau. [Prefácio]. In: HAVEL, Václav. Cartas a Olga. São Paulo: Estação Liberdade, 1992.

SPINKA, Matthew. John Hus: a biography. Princetown: Princetown University Press, 1968.

TANNER, John R.; PREVITÉ-ORTON, C. W.; BROOKE, Z. N. (Eds.). The Cambridge medieval history: decline of empire and papacy. v. 7. Cambridge: Cambridge University Press, 1968.

THOMSON, S. Harrison. The Czechoslovaks to 1620. In: KERNER, Robert (Ed.). Czecholosvakia: twenty years of independence, 1940. Berkeley; Los Angeles: University of California Press, 1945. p. 8-28.

Submetido em: 28.02.2014

Aprovado em: 13.08.2014

Thiago Borges de Aguiar é doutor em educação pela Universidade de São Paulo e professor do Programa de Pós-Graduação em Educação da Universidade Metodista de Piracicaba.

Davi Costa da Silva é bolsista de iniciação científica e graduando em ciências sociais pela Universidade de São Paulo. 